\title{
Oral complications of radiotherapy in the head and neck
}

\section{Bruno Correia Jbam ', Addab Regina da Silva Freire $^{2}$}

Keywords: Radiotherapy. Oral complications. Head and neck cancer

\section{Summary}

\begin{abstract}
$\mathrm{R}$ head and neck malignancies. However, high doses of radiation in large areas, including the oral cavity, maxilla, mandible and salivary glands may result in several undesired reactions. Mucositis, candidosis, disgeusia, radiation caries, osteoradionecrosis, soft tissue necrosis and xerostomia are some of radiotherapy's complications. Aim: The aim of this study is to briefly review the side effects that may be seen in the oral cavity during or after radiotherapy treatment in the head and neck region. Basic method used: Review of relevant literature. Study design: Literature review. Results: Radiotherapy is still associated with several side effects, significantly affecting patients' quality of life. Conclusions: A multidisciplinary treatment, including physicians, dentists, speech therapits, nutritionists, and psychologists, is the best alternative to minimize, or even prevent such reactions.
\end{abstract}

${ }^{1}$ M.Sc. in Stomatology, Post-Graduate student

${ }^{2} \mathrm{PhD}$ in Biology and Oral-Dental Pathology, Assistant Professor at Minas Gerais Federal University Dental School. Federal University of Minas Gerais, Dental School

Mail address: Bruno Correia Jham - Av. Olegário Maciel 2063 apto. 303 Lourdes Belo Horizonte MG 30180-112.

Coordination for Post-Graduates Improvement Program (CAPES).

Paper submitted to the ABORL-CCF SGP (Management Publications System) on September 19th, 2005 and accepted for publication on April 23 rd, 2006. Cod. 1442. 


\section{INTRODUCTION}

Every year, about 870,000 new cases of malignant tumors on the upper airways and digestive passages are diagnosed in the world. ${ }^{1}$ In developing countries, only neck cancer rates are higher than the incidence rates of these malignancies. ${ }^{2}$ The choice treatment for these malignancies is surgery, associated or not to radiotherapy. Surgery and radiotherapy are the treatment options for the localized or regional disease. ${ }^{3,4}$

Many patients with head and neck cancer are submitted to high doses of radiotherapy in large areas including oral cavity, maxilla, mandible and salivary glands. Despite having the advantage of preserving the tissue structure, radiotherapy causes many adverse reactions in the oral cavity. ${ }^{5}$ Since radiotherapy-induced oral complications cause high morbidity and a decrease in quality of life, the aim of this review is to tackle the main adverse oral effects caused by radiotherapy.

\section{Biological aspects of radiotherapy}

Radiotherapy is a treatment option for malign tumors whose therapeutic agent is ionizing radiation, that is to say, the type of radiation that promotes ionization in the area in which it is applied, making it electrically unstable. Ionizing radiations are divided into the corpuscular and electromagnetic ones. Corpuscular radiations are represented by electrons, protons and neutrons; electromagnetic radiations are called photons, being represented by $\mathrm{X}$ rays and by gamma rays. In the clinical practice, most radiotherapy treatments are done through the use of photons. ${ }^{6}$

Ionizing radiations act on the nuclear DNA leading to death or loss of its reproductive capacity. Since DNA content duplicates during mitosis, those cells with a high degree of mitotic activity are more radiosensitive than those with low mitotic rate. Radiation action can be direct or indirect. On the direct action, the DNA molecule is cleaved, interfering in the duplication process. On the indirect effect, water is dissociated into its two elements, $\mathrm{H}+$ and $\mathrm{OH}$; the latter reacts with the basis of DNA, interfering in the duplication process. Since water represents most part of cell content, the indirect effect is proportionally more important than the direct one. ${ }^{7}$

Due to the fact of being in a continuous multiplying process, malignant cells can suffer the radiation effects. However, the multiplying ability varies according to cell type. Thus, there is a radiosensitivity scale both for tumor and normal cells. Embryonic malignancies and lymphomas are radiosensitive tumors, whereas carcinomas are moderately radiosensitive. ${ }^{8}$

In order to express the amount of absorbed radiation by the tissues, an international unit, rad (radiation absorbed dose) was initially proposed, that is to say, the difference between the applied radiation and that which went through the tissues. Recently, this unit was replaced by Gray, defined as 1 joule per kilogram. Gy is short for Gray, thus: $1 \mathrm{~Gy}=100 \mathrm{cGy}=100 \mathrm{rad} ., 10$

Radiotherapy can be administered in short duration schemes up to extremely long schemes, lasting for several weeks. The justification for applications in small daily fractions is based on radiobiology "5 Rs": reoxygenation, redistribution, recruitment, repopulation and regeneration. ${ }^{6}$ Most patients on radiotherapy receive a total dose of 50-70 Gy as curative dose. These doses are fractioned during a period of 5-7 weeks, once a day, 5 days a week, with a daily dose of approximately $2 \mathrm{~Gy}$. On the concomitant treatment, $45 \mathrm{c}$ Gy are used on the pre-operative stage and 55-60 Gy on the post-operative. ${ }^{11}$

\section{Oral complications of radiotherapy}

Adverse reactions to radiotherapy will depend on the volume and area being irradiated, on the total dose, on the fractioning, on the age, on the patient's clinical conditions and on the associated treatments. A small increase on tumor dosage is enough for a significant increase on the complications incidence. Acute reactions happen during the treatment and most of the time, they are reversible. Late complications are normally irreversible, leading to permanent incapability and to a worsening of quality of life ${ }^{5}$, and they vary on intensity, being normally classified into mild, moderate and severe. ${ }^{7}$

Many head and neck cancer patients are submitted to high doses of radiotherapy on large areas of radiation including the oral cavity, maxilla, mandible and salivary glands. Thus, anti-cancer therapy is associated with several adverse reactions. These reactions can occur in an acute stage (during or at the weeks right after treatment) or in a chronic stage (months or years after radiotherapy). The severity of acute oral complications will depend on the inclusion degree of these structures on the radiated area. ${ }^{5,12}$

\section{Mucositis}

Mucositis is defined as a mucosal irritation..$^{5}$ Anti-neoplastic-therapy-induced mucositis is a significant adverse reaction that may interfere on the radiotherapy process altering the tumor local control and therefore, the patient's survival. Mucositis is believed to occur in four stages (inflammatory/vascular, epithelial, ulcerative/bacteriologic and healing). The most used scale to measure oral mucositis is the one by the WHO, which classifies mucositis into four degrees. Degree 0 is when there are no signs or symptoms. Degree 1 is when the mucosa is erythematose and painful. Degree 2 is characterized by ulcers, and the patient can eat normally. Degree 3 is when the patient has ulcers and can only drink fluids. Finally, degree 4 is when the patient cannot eat or drink. ${ }^{13}$

Due to oral mucosa damages, patients will complain 
of pain, what may lead to the need of using painkillers during treatment. The pain intensifies whenever the patient tries to eat or drink. ${ }^{5}$ Mucositis is even worse when chemotherapy is used in association with radiotherapy in cancer treatment. ${ }^{14}$

\section{Candidosis}

Radiated patients are more prone to developing oral infections caused by fungi and bacterias. ${ }^{15}$ Studies have showed that patients submitted to radiotherapy have a higher number of microbian species, such as Lactobacillus spp., Streptococcos aureus and Candida albicans. ${ }^{9}$ Oral candidosis is a common infection in patients being treated for upper airways and digestive tract malignancies. Colonization of oral mucosa can be found in as many as 93\% of these patients, whereas Candida infection can be found in $17-29 \%$ of patients submitted to radiotherapy. The increased risk for oral candidosis is likely to be the result of the drop in salivary flow as a consequence of radiotherapy. ${ }^{16,17}$ Besides, a possible explanation for a higher predisposition of irradiated patients to candidosis is a reduced phagocytic activity of salivary granulocytes against these micro-organisms. ${ }^{18}$

Clinically, candidosis can be seen both in its pseudomembranous and erythematous forms. The latter can be of difficult diagnosis, and it may be confused with irradiation induced mucositis. Patients complain more of pain and / or burning sensation. ${ }^{16,17}$

Ramirez-Amador et al. ${ }^{17}$ verified that Candida prevalence in patients increased from $43 \%$ in the first visit to the doctor's office to $62 \%$ during radiotherapy and finally to $75 \%$ during post-radiotherapy control visits. In the study by Redding et al. ${ }^{19}, 73 \%$ of patients analyzed showed colonization by Candida, whereas $27 \%$ of them had the infection. The study by Grotz et al. ${ }^{20}$ analyzed colonization by Candida in irradiated patients. They verified that the maximum colonization rate happened six months after radiotherapy, and 12 months after radiotherapy the values went back to be lower than normal.

Several studies have already analyzed which Candida species were involved in colonization and infection of radiated patients. Previous studies ${ }^{16,17}$ showed that Candida albicans was the most prevalent micro-organism. However, other species had been identified recently. C. glabrata e C. krusei micro-organisms had already been seen in patients submitted to radiotherapy. ${ }^{21}$ Recent studies found a relation between oral candidosis and C. dubliniensis species. In this study, the authors suggest that the species C. albicans and C. dubliniensis probably act together in the infections that affect radiated patients. ${ }^{22,23}$ Besides, it is known that the non-albicans species distribution varies according to geographical location. Thus, in North America, the predominant species is C. glabrata. Whereas a study done in Brazil showed that the predominant species is C. tropicalis. ${ }^{24}$

\section{Dysgeusia}

Dysgeusia affects patients from the second or third week of radiotherapy onwards, and it may last for several weeks or even months. It occurs because the taste buds are radiosensitive, with the degeneration of their normal histological architecture. The increase of salivary flow viscosity and the saliva biochemical alteration creates a mechanical barrier of saliva which makes it difficult the physical contact between the tongue and foodstuff. The recovery until reaching almost normal levels generally takes place around 60 to 120 days after the end of the radiation. Studies show that dysgeusia is a complaint by approximately $70 \%$ of patients submitted to radiotherapy, also implying in the loss of appetite and weight, being the most uncomfortable complication for most radiated patients. $5,14,25$

\section{Radiation caries}

Even patients who had not experienced tooth decay for some time, may develop radiation caries when submitted to radiotherapy. ${ }^{26}$ The main factor for the development of such injuries is the decrease of saliva amount and its qualitative alterations ${ }^{27}$ Besides, radiation has a direct effect on teeth, making them more susceptible to decalcification. ${ }^{26}$

\section{Osteoradionecrosis}

Osteoradionecrosis (ORN) is a bone ischemic necrosis caused by radiation, being one of the most serious consequences of radiotherapy, causing pain as well as possible substantial loss of bone structure ${ }^{5,28}$ Due to anticancer therapy, bone cells and the vascularization of bone tissue may suffer irreversible injuries. ${ }^{26}$ ORN may occur spontaneously or more commonly, after trauma (generally dental extractions). In 95\% of cases ORN is associated with soft tissue necrosis and subsequent bone exposure..$^{28}$ Mandibles are more affected than maxillas and patients with their natural teeth have greater chances of developing ORN. Spontaneous bone exposure occurs approximately one year after finishing radiotherapy and the risk of developing this complication remains indefinitely. ${ }^{26}$ Besides, studies show that approximately $60 \%$ of patients complain of pain, ranging from mild pain, controlled with drugs, to extremely painful conditions. However, the presence of these symptoms does not appear to be related to the extension of the process. ORN may also result in edema, suppuration and pathological fractures, which may occur in $15 \%$ of patients, always experienced together with pain. ${ }^{28}$

\section{Soft tissue necrosis}

Another possible consequence of radiotherapy is 
soft tissue necrosis, which may be defined as an ulcer located in the radiated tissue, without the presence of residual malignancy. The occurrence of soft tissue necrosis is related to dose, time and volume of the radiated gland, when the brachytherapy is used, the risk is higher. Soft tissue necrosis is a normally painful condition and good oral hygiene together with the use of painkillers and often times, antibiotics, are necessary to manage the condition. Since ulcerations are often seen on the tumor primary site, regular evaluations are necessary until the necrosis retreats, therefore excluding the possibility of recurrence. ${ }^{26}$ Besides, soft tissues may suffer fibrosis after radiotherapy, becoming pale, thin and without flexibility. When fibrosis affects chewing musculature (temporal, masseter and pterygoid muscles) trismus can happen. In the most serious cases, trismus may interfere with eating and dental care. ${ }^{5}$

\section{Xerostomia}

Xerostomia, or "dry mouth", can result from some diseases or it can be an adverse reaction to some drugs. 29 Among radiated patients in the head and neck area, it is one of the most frequent complains. ${ }^{30}$ Chencharick and Mossman $^{25}$ noticed that $80 \%$ of radiated patients complain of xerostomia. However, the relation between the individual perception of dry mouth and the real values of salivary flow havr not yet been completely defined. ${ }^{31}$ In some situations, there is a co-relation between reduced salivary flow and xerostomia complaint. ${ }^{32}$ However, in many cases there is not a relation between xerostomia and objective findings of salivary gland dysfunction - that is to say, patients without alterations of salivary flow may complain of mouth dryness. Patients with xerostomia complain of oral discomfort, taste loss, speech and swallowing difficulties. ${ }^{33}$ Saliva also suffers qualitative alterations resulting from radiotherapy with decrease of amylase activity, buffer capacity and $\mathrm{pH}$, with consequent acidification. There are also alterations of several electrolytes such as calcium, potassium, sodium and phosphate ${ }^{.32-26}$ Thus, individuals who were radiated are more susceptible to periodontal disease, rampant tooth decay and oral infections by fungus and bacteria. ${ }^{15}$

Xerostomia treatment can be done through the use of mechanic/taste stimulants, saliva substitutes or systemic agents. ${ }^{37,38}$ Alternative methods, such as acupuncture, had also been mentioned as treatment options for xerostomia. ${ }^{39}$ Generally speaking, stimulants and saliva substitutes only reduce xerostomia, without altering salivary flow. On the other hand, systemic agents besides reducing xerostomia, also decrease oral problems associated with salivary glands hypofunction, through the increase of salivary flow. Thus, the treatment of choice for radiotherapy-induced xerostomia, should be through the use of systemic agents, and pilocarpine is the most studied one among them. Besides, studies show that systemic agents, such as pilocarpine, are more effective when used during radiotherapy. ${ }^{34,40}$ This has also been recently showed for betanechol, when the drug used concomitantly with radiotherapy is able to increase salivary flow at rest, right after the end of the radiotherapy treatment, besides decreasing the subjective complaint of dry mouth. ${ }^{41}$

\section{CONCLUSIONS}

Radiotherapy has been widely used in treating malignant lesions on the head and neck, with improvement in patient survival rates. However, this therapy is still associated with several adverse reactions that affect patient quality of life significantly, and may even affect the progress of the treatment. Taking into account that the occurrence of head and neck cancer rates are probably going to be the same as last decades, it is extremely important that health professionals are familiarized with the complications that may result from anti-neoplastic treatments. Multidisciplinary treatment, including medical team, dental surgeons, speech therapists, nutritionists and psychologists, is the best option in order to minimize or even prevent such complications.

\section{REFERENCES}

1. Parkin DM, Pisani P, Ferlay J. Estimates of worldwide incidence of eighteen major cancers in 1985. Int J Cancer 1993;54:594-606.

2. Muir CS, Wagner G, Demaret E, Nagy-Tiborcz A, Parkin DM, Schlaefer K, Villhauer-Lehr M, Whelan S. Directory of on-going research in cancer epidemiology 1986. IARC Sci Publ 1986;80:1-805.

3. Mantravadi RV, Haas RE, Liebner EJ, Skolnik EM, Applebaum EL. Postoperative radiotherapy for persistent tumor at the surgical margin in head and neck cancers. Laryngoscope 1983;93:1337-40.

4. Spaulding CA, Korb LJ, Constable WC, Cantrell RW, Levine PA. The influence of extent of neck treatment upon control of cervical lymphadenopathy in cancers of the oral tongue. Int J Radiat Oncol Biol Phys 1991;21:577-81.

5. Spetch L. Oral complications in the head and neck irradiated patient. Introduction and scope of the problem. Supp Care Dent 2002;10:369.

6. Novaes PERS. Radioterapia. In: Brentani MM, Coelho FRG, Iyeyasu H, Kowalski LP, editores. Bases da oncologia. 1.ed. Sao Paulo: Ed. Marina; 1998.

7. Murad AM, Katz A. Oncologia: bases clínicas do tratamento. 1.ed. Rio de Janeiro: Guanabara Koogan; 1996.

8. Salvajoli JV, Souhami L, Faria SL. Radioterapia em oncologia. 1.ed. Rio de Janeiro: Ed. Médica e Científica Ltda.; 1999.

9. Rothwell BR. Prevention and treatment of the orofacial complications of radiotherapy. JADA 1987;114:316-22.

10. Kowalski LP, Agnelli A, Salvajoli JV, Lopes LF. Manual de condutas diagnósticas e terapêuticas em oncologia. 2.ed. São Paulo: FAP 2002.

11. Tsujii II. Quantitative dose-response analysis of salivary function following radiotherapy using sequential RT-sialography. Int J Radiat Oncol Biol Phys 1985;11:1603-12.

12. Barasch A, Safford M, Eisenbeg E. Oral cancer and oral effects of anticancer therapy. Mt Sinai J Med 1998;65:370-7.

13. Pico JL, Avila-Gavarito A, Naccache P. Mucositis: its occurence, consequences and treatment in the oncology setting. Oncol Phys Educ 1998;3:446-51.

14. Ohrn KEO, Wahlin Y, Sjoden P. Oral status during radiotherapy and 
chemotherapy: a descriptive study of patient experiences and the occurrence of oral complications. Supp Care Cancer 2001;9:247-57.

15. Hancock PJ, Epsten JB, Sadler GR. Oral and dental management related to radiation therapy for head and neck cancer. J Can Dent Assoc 2003;69:585-90.

16. Silverman S Jr, Luangjarmekorn L, Greenspan D. Occurrence of oral candida in irradiated head and neck cancer patients. J Oral Med 1984;39:194-6.

17. Ramirez-Amador V, Silverman S Jr., Mayer P, Tyler M, Quivey J. Candidal colonization and oral candidiasis in patients undergoing oral and pharyngeal radiation therapy. Oral Surg Oral Med Oral Pathol Radiol Endod 1997;84:149-53.

18. Ueta E, Osaki T, Yoneda K, Yamamoto T. Prevalence of diabetes mellitus in odontogenic infections and oral candidosis. J Oral Pathol Med 1993;22:168-74.

19. Redding SW, Pfaller MA, Messer SA, Smith JA, Prows J, Bradley LL, et al. Variations in fluconazole susceptibility and DNA subtyping of multiple Candida albicans colonies from patients with AIDS and oral candidiasis suffering one or more episodes of infection. J Clin Microbiol 1997;35:1761-5.

20. Grotz KA, Genitsariotis S, Vehling D, Al-Nawas B. Long term oral Candida colonization, mucositis and salivary function after head and neck radiotherapy. Supp Care Cancer 2003;11:717-21.

21. Mucke R, Kaben U, Libera T, Knauerhase H, Ziegler PG, Hamann D, Strietzel M. Fluconazole prophylaxis in patients with head and neck tumours undergoing radiation and radiochemotherapy. Mycoses 1998;41:421-3.

22. Redding SW, Zellars RC, Kirkpatrick WR, Mcatee RK, Caceres MA, Fothergill AW, et al. Epidemiology of Oropharyngeal Candida colonization and infection in patients receiving radiation for head and neck cancer. J Clin Microbiol 1999;37:3896-900.

23. Redding SW, Bailey CW, Lopez-Ribot JL, Kirkpatrick WR, Fothergill AW, Rinaldi MG, Patterson TF. Candida dubliniensis in radiationinduced oropharyngeal candidiasis. Oral Surg Oral Med Oral Pathol Radiol Endod 2001;9:659-62.

24. Jham BC, Françca EC, Reis RR, Santos VR, Kowalski LP, Freire ARS. Candida oral colonization and infection in Brazilian patients undergoing radiotherapy in the head and neck: a pilot study. Oral Surg Oral Med Oral Pathol Oral Radiol Endodontol. In press, 2006.

25. Chencharick JD, Mossman KL. Nutritional consequences of the radiotherapy of head and neck cancer. Cancer 1983;51:811-5.

26. Silverman, S.Jr. Oral cancer. Complications of therapy. Oral Surg Oral Med Oral Pathol Oral Radiol Endond 1999;88:122-6.

27. Epstein JB, Chin EA, Jacobson JJ, Rishiraj B, Le N. The relationships among fluoride, cariogenic oral flora, and salivary flow during radiation therapy. Oral Surg Oral Med Oral Pathol 1998;86:286-92.
28. Thorn JJ, Hansen HS, Spetch L, Bastholt L. Osteoradionecrosis of the jaws: clinical characteristics and relation to field of irradiation. J Oral Maxillofac Surg 2000;58:1088-93.

29. Porter SR, Scully C, Hegarty AM. An update of the etiology and management of xerostomia. Oral Surg Oral Med Oral Pathol Oral Radiol Endod 2004;97:28-46.

30. Guchelaar HJ, Vermes A, Meerwaldt JH. Radiation induced xerostomia: pathophysiology, clinical course and supportive treatment. Support Care Cancer 1997;5:281-8.

31. Logemann JA, Smith CH, Pauloski BR, Rademaker AW, Lazarus CL, Colangelo LA, et al. Effects of xerostomia on perception and performance of swallow function. Head and Neckm, 2001;23:317-21.

32. Pow EHN, Mcmillan AS, Leung WK, Wong MCM, Kwong DL. Salivary gland function and xerostomia in southern Chinese following radiotherapy for nasopharyngeal carcinoma. Clin Oral Invest 2003;7:2304.

33. Davies AN, Broadley K, Beighton D. Salivary gland hypofunction in patients with advanced cancer. Oral Oncol 2002:38:680-5.

34. Makkonen TA, Tenovuo J, Vilja P, Heimdahl A. Changes in the protein composition of whole saliva during radiotherapy in patients with oral or pharyngeal cancer. Oral Surg Oral Med Oral Pathol 1986;62:2705.

35. Almstahl A, Wikstrom M, Stenberg I, Jakobsson A, Fagerberg-Mohlin B. Oral microbiota associated with hyposalivation of different origins. Oral Microbiol Imunol 2003;18:1-8.

36. Möller P, Perrier M, Ozsahin M, Monnier P. A prospective study of salivary gland function in patients undergoing radiotherapy for squamous cell carcinoma of the oropharynx. Oral Surg Oral Med Oral Pathol Oral Radiol Endod 2004;97:173-89.

37. Davies AN. The management of xerostomia:a review. Eur J Cancer Care 1997;6:209-14.

38. Amerongen AVN, Veerman ECI. Current therapies for xerostomia and salivary gland hypofunction associated with cancer therapies. Supp Care Cancer 2003;11:226-31.

39. Johnstone PAS, Peng P, Byron CM, Inouye WS, Niemtzow RC. Acupunture for pilocarpine-resistant xerostomia following radiotherapy for head and neck malignancies. Int J Radiat Oncol Biol Phys 2001;50:353-7.

40. Davies AN, Singer J. A comparison of artificial saliva and pilocarpine in radiation induced xerostomia. J Laryngol Otol 1994;108:663-5.

41. Jham BC, Teixeira IV, Aboud CG, Carvalho AL, Coelho MM, Freire ARS. A randomized phase III prospective trial of bethanechol to prevent radiotherapy-induced salivary gland damage in patients with head and neck cancer. Oral Oncol. In press 2006. 